\title{
Evaluation of the effect of gabapentin on postoperative analgesia with epidural morphine after abdominal hysterectomy
}

\author{
Diptesh Aryal, Renu Gurung, Moda Nath Marhatta \\ Department of Anesthesiology, Maharajgunj Medical Campus, Institute of Medicine, Tribhuvan University, \\ Kathmandu, Nepal
}

\begin{abstract}
Correspondence
Dr. Diptesh Aryal

Department of Anesthesiology, Maharajgunj Medical Campus, Institute of Medicine, Tribhuvan University, Kathmandu, Nepal
\end{abstract}

\section{Email:}

diptesharyal@gmail.com

\section{ORCID ID:}

http://orcid.org/0000-0002-1431-8293

DOI: http://dx.doi.org/10.3126/ jcmsn.v13i2.16427

Article received: $30^{\text {th }}$ Jan 2017 Article accepted: $27^{\text {th }}$ June 2017

\begin{abstract}
Background \& Objectives: Gabapentin has been used successfully as a non-opioid analgesic adjuvant for postoperative pain management. We hypothesized that the preoperative use of gabapentin prolonged the analgesic effect of epidural morphine without an increase in adverse effects of morphine. Materials \& Methods: In a randomized, double blind study sixty ASA PS I and II patients undergoing abdominal hysterectomy were assigned to receive either placebo or gabapentin $1200 \mathrm{mg} 1$ hour before surgery. Postoperatively, $0.125 \%$ bupivacaine with morphine 50 $\mu \mathrm{g}$ per kg body weight was used for epidural analgesia. Vital parameters, time to the first request for analgesic, visual analogue scale scoring for pain at rest and during movement, 24-hour morphine consumption, and side effects were studied. Results: The patients were comparable with respect to age, weight, ASA PS, baseline hemodynamic parameters and duration of surgery. Gabapentin significantly decreased the duration of analgesia compared to placebo (1078.26 min Vs. $303.5 \mathrm{~min}$; P value $<0.0001)$. The VAS scores at rest and during movement at $1,2,4,8,12$, and $24 \mathrm{~h}$ were significantly lower in gabapentin group. The total amount of morphine consumption in $24 \mathrm{~h}$ postoperatively was significantly lower in gabapentin group (1.93mg Vs. 6.30mg; P value $<0.0001)$. The incidence of nausea and pruritus was significantly lower with gabapentin. Conclusion: Oral gabapentin $1200 \mathrm{mg}$ as a premedication decreases the dose requirement of epidural morphine and postoperative pain after total abdominal hysterectomy. It also decreases the pain scores at rest and during movement significantly.
\end{abstract}

Key words: Abdominal hysterectomy; Epidural analgesia; Gabapentin; Morphine; Preemptive analgesia

Citation: Aryal D, Gurung R, Marhatta MN. Evaluation of the effect of gabapentin on postoperative analgesia with epidural morphine after abdominal hysterectomy. JCMS Nepal. 2017;13(2):251-7.

\section{INTRODUCTION}

According to IASP, pain is defined as "an unpleasant sensory and emotional experience associated with actual or potential tissue damage, or described in terms of such damage". ${ }^{1}$ Pain can be categorized according to duration (acute, convalescent, chronic), pathophysiologic mechanisms (physiologic, nociceptive, neuropathic), and clinical context (postsurgical, malignancy related, neuropathic, degenerative). ${ }^{2}$ Nociceptive pain is defined as noxious perception resulting from cellular damage following surgical, traumatic, or disease-related injuries. Postoperative pain is a type of acute nociceptive pain. ${ }^{2}$ It is also considered as a transient, reversible type of neuropathic pain. $^{3}$ The surgical stimulation also leads to peripheral and central sensitization, the mechanism of pain origin. ${ }^{4}$ The effective relief of pain is of paramount importance for humanitarian reasons as well as there are significant physiological benefits. Inadequate pain management results in emotional and physical suffering for the patient, sleep disturbance, tachycardia, hypertension, myocardial ischemia and infarction, impaired bowel 
movement and respiratory failure. ${ }^{4-8}$ Postoperative pains are not purely nociceptive in nature, and may consist of inflammatory, neurogenic, and visceral components. ${ }^{9}$ Opioid analgesics remain the primary pharmacologic therapy for moderate to severe postoperative pain. ${ }^{10}$ But their use is limited by adverse effects, such as nausea, urinary retention, vomiting, pruritus and sedation. ${ }^{11}$ Local anesthetic techniques are often short-lived or require interventional procedures. The use of NSAIDs and COX-2 inhibitors is limited by complications like gastrointestinal, renal and hematological toxicities. So a single agent or technique cannot be appropriate in the perioperative setting. Therefore a multimodal method is the best method of managing postoperative pain. The concept of preemptive analgesia is a novel approach in the methods of postoperative pain management. Preemptive analgesia is the anti-nociceptive treatment given before the noxious event like surgery to prevent the establishment of altered central processing of afferent input and consequently decreases the incidence of hyperalgesia and allodynia postoperatively. ${ }^{12-14}$ Oral gabapentin is one of the methods of delivering preemptive analgesia. Gabapentin, a structural analog of gamma-amino butyric acid, has been effective in neuropathic pain, ${ }^{15}$ diabetic neuropathy, ${ }^{16}$ post herpetic neuralgia ${ }^{17}$ and reflex sympathetic dystrophy. ${ }^{18}$ Gabapentin has a selective effect on the nociceptive process involving central sensitization. It also reduces the hyper excitability of dorsal horn neurons induced by tissue injury. ${ }^{19-20}$ Thus its pretreatment is effective in the management of postoperative pain and blocking the development of hyperalgesia. $^{21}$ There are pharmacodynamic and pharmacokinetic interactions between morphine and gabapentin, which lead to an augmentation of their analgesic effect. ${ }^{22}$ Therefore gabapentin is effective in reducing pain intensity, opioid consumption and opioid-related adverse effects after surgery. Gabapentin has very few adverse effects of its own. ${ }^{23}$ With this background, this study has been designed to test the hypothesis that the preoperative use of oral gabapentin will prolong the analgesic effect of epidural morphine without an increase in adverse effects of morphine, and thus reduce consumption of epidural analgesics after elective lower abdominal surgery.

\section{MATERIALS AND METHODS}

This is a prospective, randomized, placebo- controlled, double-blinded study conducted at Tribhuvan University Teaching Hospital from 2010 to 2011. After the approval of the Institutional Review Board of Institute of Medicine, Kathmandu, Nepal, the eligible consenting patients were evaluated pre-operatively, and randomly assigned to one of the two study groups using a sealed envelope technique. Each group had a sample size of 30 patients. Inclusion criteria included ASA physical status I and II patients, aged 18 to 65 years, undergoing elective abdominal hysterectomy surgery. The patients were randomized to get either oral placebo tablets or oral gabapentin tablets of dose $1.2 \mathrm{~g}$ one hour before surgery. Informed consent was obtained from all the participating patients. Patients with ASA physical status - grade III or more, known history of hypersensitivity to any drug used in this study, history of drug or alcohol abuse, patients having coagulation disorder, patients taking anticoagulants, with history of chronic pain conditions, and who have taken NSAIDs in last 24 hours were excluded. The patients were counseled about methods of measuring postoperative pain, sedation, dizziness, nausea and vomiting, and pruritus. The patients were fasted for six hours preoperatively. They received the study drugs in the morning of the surgery as per the randomization. In the preparation room, baseline systolic and diastolic pressure, heart rate, respiration rate and oxygen saturation were recorded. The epidural catherization and general anesthesia procedures were conducted according to standard protocol. Intraoperative systolic, diastolic, mean arterial pressure, heart rate and rhythm, and peripheral oxygen saturation readings were monitored.

After completion of surgery, a loading dose of bupivacaine $0.125 \%$ with morphine $50 \mu \mathrm{g}$ per $\mathrm{kg}$ body weight with total volume of $8 \mathrm{ml}$ was administered through the epidural catheter. After the end of surgery, patient was transferred to the recovery room. The time in the recovery room when patient was fully conscious was recorded as time 0. Assessments of systolic blood pressure, diastolic blood pressure, pulse rate, respiration rate were done hourly for first 12 hours, then four hourly for the next 12 hours. Assessments of pain, sedation, nausea, vomiting, dizziness and pruritus were performed at $0,1,2,4,8,12$ and $24 \mathrm{~h}$ after arrival in the post anesthesia care unit or postoperative ward. Assessment of postoperative pain was done, at rest and on movement, with 
Visual analogue scale (VAS). Patients received postoperative analgesia with an epidural solution containing bupivacaine $0.125 \%$ and morphine 50 $\mu \mathrm{g}$ per $\mathrm{kg}$ body weight, total volume $8 \mathrm{ml}$ when patient complained of pain and VAS was more than three. The time of the first postoperative epidural analgesia injection was recorded. The minimum interval between two successive doses was 30 minutes. Total morphine consumption for each patient was recorded from 0 to $24 \mathrm{~h}$ postoperatively. The misplacement of catheter was suspected when pain was not relieved and VAS was $>3$ after two consecutive epidural analgesics in the postoperative ward. These patients were excluded from the study. Injection Tramadol 50mg IV was used as rescue analgesia. The epidural morphine administration was stopped in case of a sedation score equaled 3 or respiratory depression.

\section{RESULTS}

The mean age in gabapentin group was $42.26 \pm 6.8$ years, and in control group $44.86 \pm 9.25$ years. The patients in both the groups were comparable in terms of weight, ASA physical status, heart rates, blood pressure, respiratory rate and oxygen saturation. The majority of the patients in the study underwent total abdominal hysterectomy for fibroid uterus. There was no significant difference in duration of surgery between the gabapentin and placebo group $(99.63) \pm 24.73$ vs. $100 \pm 20.02$ minutes, $\mathrm{p}=0.927)$. $(\mathrm{P}=0.855)$. The mean bolus

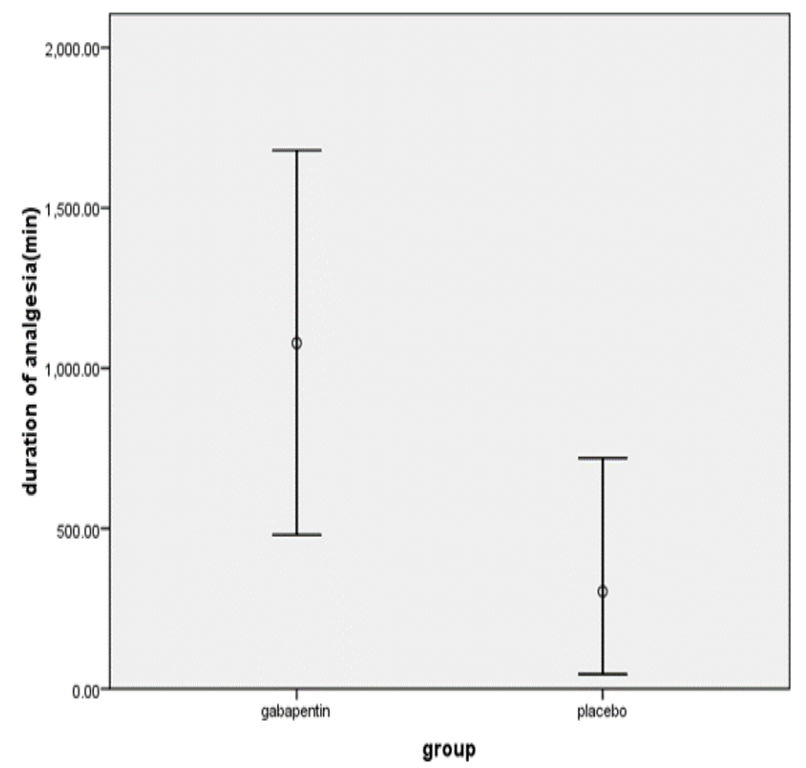

Figure 1: Duration of analgesia of first epidural analgesia (maximum, minimum and mean in minutes) epidural dose in the gabapentin group was $2.77 \pm$ $0.477 \mathrm{mg}$ while in the placebo group it was $2.79 \mathrm{mg}$ $\pm 0.435 \mathrm{mg} \quad(\mathrm{p}=0.855)$. The mean duration of analgesia after the initiation of the epidural analgesia was compared between the two groups. Ten cases in gabapentin group did not need any epidural morphine top up in the 24 hours postoperatively. They were followed further for first analgesia requirement. The mean duration of analgesia after the first dose of epidural analgesia was $1078.26 \pm 418.46$ minutes in gabapentin group while in the placebo group, it was $303.5 \pm 193.72$ minutes $(p<0.0001)$ as shown in figure 1 .

There was significant difference in the number of postoperative epidural analgesic top up between gabapentin and placebo groups $(\mathrm{P}<0.0001)$. The mean number of top up in the gabapentin group was $0.7 \pm 0.53$ while it was $2.26 \pm 0.58$ in the placebo group. The total amount of morphine consumption was significantly different between gabapentin and placebo group $(1.93 \pm 1.5$ vs. $6.30 \pm 1.82 \mathrm{mg}, \mathrm{p}<$ $0.0001)$, shown in figure 2. The VAS scores for pain at both the rest and during movement were significantly lower in the gabapentin group compared with the placebo group. Patients in the gabapentin group had significantly lower VAS scores at all times $0,1,2,4,8,12$ and 24 hours than those in the placebo group as shown in figure 3 . There was no episode of hypotension, bradycardia or respiratory depression in any case in 24 hours postoperatively. In the postoperative period, the

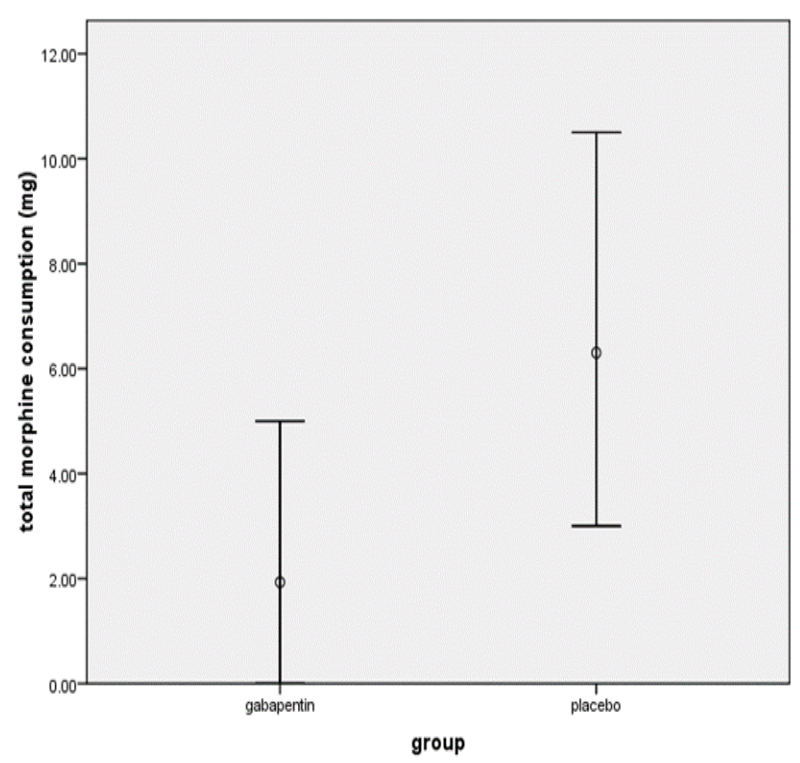

Figure 2: Total morphine consumption in $24 \mathrm{~h}$ (maximum, minimum and mean) 


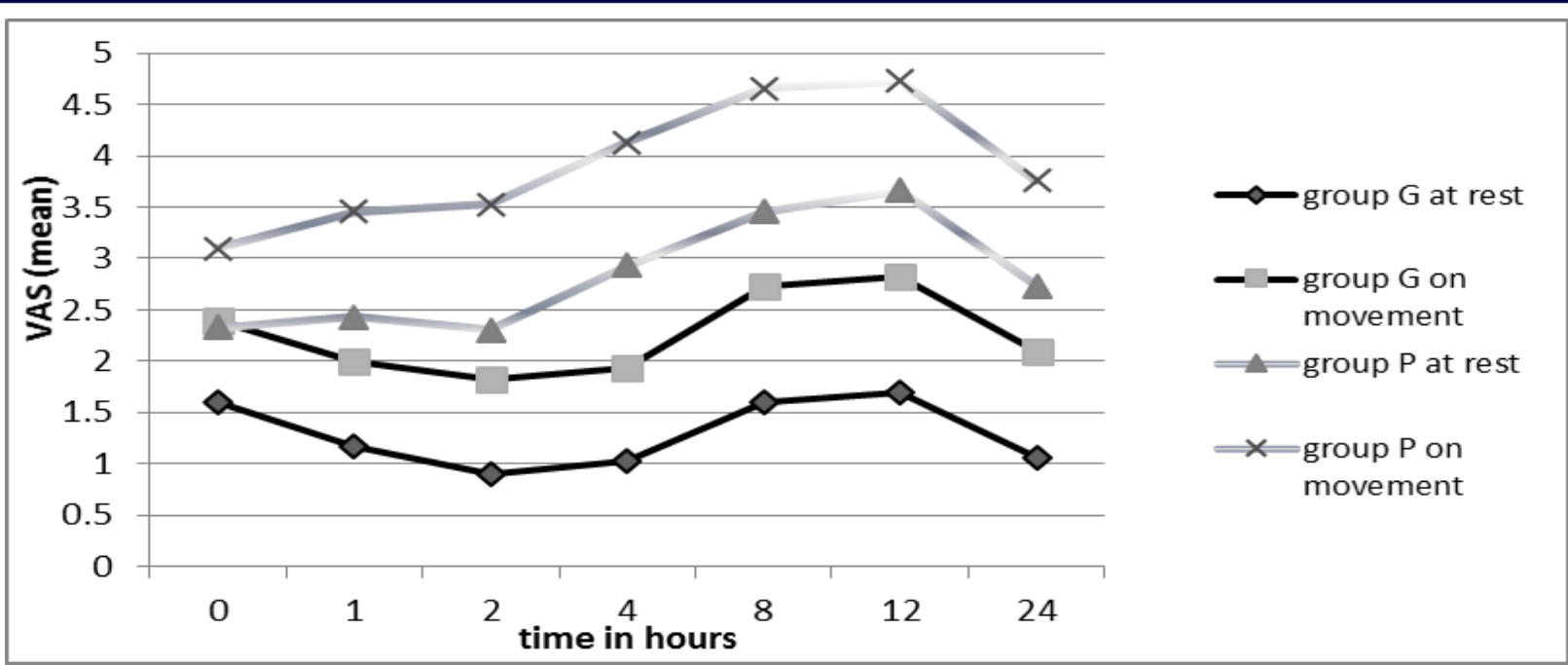

Figure 3: Postoperative Pain Scores in Gabapentin (G) and Placebo (P) Groups

patients in gabapentin group had fewer side effects such as nausea, vomiting, dizziness and pruritus when compared with placebo. The incidence of nausea and pruritus was significantly lower in the gabapentin group compared to the placebo group.

\section{DISCUSSION}

Our study shows that the preemptive administration of gabapentin $1200 \mathrm{mg}$ significantly reduces the incidence of pain after abdominal hysterectomy. Postoperatively, patients who received preemptive gabapentin had significantly lower pain scores at 1 , $2,4,8,12$ and $24 \mathrm{~h}$ and had significantly decreased total morphine requirements in the initial $24 \mathrm{~h}$ in comparison to the placebo group. The duration of analgesia was also significantly prolonged in the gabapentin group. VAS scores were significantly lower at both the rest and during movement compared to the placebo group. The patients in gabapentin group had fewer side effects such as nausea, vomiting and pruritus when compared with placebo. The incidence of nausea and pruritus was significantly lower in the gabapentin group compared to the placebo group. Our study shows the usage of gabapentin for preemptive analgesia as an adjuvant to regional analgesia technique consisting of morphine. The main aim of combining different analgesic drugs and techniques is to obtain synergistic or additive actions that allow a smaller dose of each agent to be used and, thereby, improve the safety profile. Our study has achieved that aim. The demographic characteristics of patients in both gabapentin and placebo groups were comparable in our study. There was no significant difference in patient distribution in terms of age, weight, ASA PS, baseline hemodynamic parameters and the duration of surgery. The anesthetic technique too was standardized in both the groups. Therefore further analysis of findings in terms of postoperative pain management; pain scores, morphine consumption and incidence of side effects are comparable between the groups. The preemptive use of gabapentin was effective in our study and other studies have shown similar results. Its use has resulted in the decrease in postoperative morphine consumption. In the study by Dierking $G$ et al. ${ }^{24}$ gabapentin $1200 \mathrm{mg}$ was given $1 \mathrm{~h}$ before surgery and followed by gabapentin $600 \mathrm{mg} 8,16$ and $24 \mathrm{~h}$ after the initial dose in patients undergoing abdominal hysterectomy. The morphine consumption was reduced by $32 \%$ without significant effects on pain scores. The reduction in morphine consumption observed in this study may have been due to an increase in side effects like sedation and dizziness caused by gabapentin. These side effects in turn may have reduced the patients' desire for morphine consumption. But no such side effects were observed in our study. So it can be said that the decrease in morphine consumption in our study is due the analgesic interaction between gabapentin and morphine. But the dose of gabapentin in our study is less compared to the dose used in their study (1200mg Vs. 3000mg). The use of lower dose of gabapentin may have been responsible for lesser side effects in our study. In another study Turan et $\mathrm{al}^{4}$ evaluated the perioperative use of Gabapentin as a non-opioid analgesic adjuvant for postoperative pain management with patient-controlled epidural 
analgesia. When gabapentin $1.2 \mathrm{~g}$ was given $1 \mathrm{~h}$ before and for 2 days after surgery the VRS pain scores were significantly lower at 1, 4, 8, 12, and $16 \mathrm{~h}$ postoperatively in patients receiving gabapentin than in those receiving placebo. The study concluded that oral gabapentin given in the dose of $1.2 \mathrm{~g}$ per day as an adjunct to epidural analgesia decreased pain and analgesic consumption. However, the incidence of dizziness in their study was higher in the gabapentin group compared to placebo group (35\% Vs. 5\%). However, in our study no patient in gabapentin group and $6.7 \%$ of patients in the placebo group developed dizziness, which was statistically not significant. Although no clear causal relationship is established, the sample size of our study may not have been adequate to detect the difference in incidence of dizziness between the two groups. Otherwise the findings in this study are comparable to the findings of our study. In another study by Alparslan et al.25, when gabapentin $1200 \mathrm{mg}$ was given $1 \mathrm{~h}$ before abdominal hysterectomy, theVAS scores in the sitting and supine position at $1,4,8,12,16$, and $20 \mathrm{~h}$ were significantly lower in the gabapentin group when compared with the placebo group upto $20 \mathrm{~h}$ after surgery. These findings are similar to those in our study. The tramadol consumption was significantly less in the gabapentin group. Sedation scores were similar at all the measured times. There were no differences between groups in adverse effects.

The study by Verma A et al.26 has shown results similar to our study. Patients receiving $300 \mathrm{mg}$ of gabapentin 2 hours before abdominal hysterectomy had significantly lower VAS scores at 2, 4, 8, 12 and $24 \mathrm{~h}$ postoperatively as compared to the placebo. Total numbers of epidural boluses were significantly less in gabapentin group $(3.4 \pm 1.6 \mathrm{Vs}$. $5.6 \pm 2.1, \mathrm{P}<0.05)$. Patients were given $12 \mathrm{ml}$ of epidural bupivaciane $0.125 \%$ bolus on demand. In our study, the mean number of top up in the gabapentin group was $0.7 \pm 0.53$ while it was 2.26 \pm 0.58 in the placebo group $(\mathrm{P}<0.0001)$. The addition of morphine in the dose of $50 \mu \mathrm{g}$ per $\mathrm{kg}$ body weight in the epidural bolus may have decreased the number of epidural boluses in our study. Another study by Dirks J A et al.27 has shown that single dose of oral gabapentin $1200 \mathrm{mg}$ resulted in an almost 50\% reduction in postoperative morphine consumption, and in a similar reduction in movement-related pain during the first $4 \mathrm{~h}$ after radical mastectomy without significant side effects, similar to our findings.
Eckhardt $\mathrm{K}$ et al. 22 have proved the reason for decreased consumption of morphine after use of oral gabapentin. The study has shown that gabapentin increases the analgesic effect of morphine. In healthy volunteers undergoing the cold pressure test, $600 \mathrm{mg}$ oral gabapentin had no analgesic effect compared with placebo. However, when the same dose of gabapentin was given with morphine, there was an analgesic effect. Serum levels of morphine were higher when volunteers were treated with morphine and gabapentin than when given morphine alone. Thus it appears that gabapentin increases the analgesic effect of morphine. The possible enhancement of morphine analgesia by gabapentin may be useful in decreasing the dose of morphine requirements postoperatively and its adverse effects. The results of our study are similar in that morphine consumption was significantly lower in gabapentin group compared to placebo group.

It is possible that gabapentin could be particularly useful in movement-related pain after surgical trauma because of its ability to prevent central neuronal sensitization. It can be speculated that measuring VAS scores on movement would be more informative than measuring them only at rest. Our study has shown significant decrease in pain scores during movement. Alparslan et al. 25 investigated, in a randomized, placebo-controlled, double-blind study, the efficacy and safety of gabapentin on pain after abdominal hysterectomy and on tramadol consumption. The VAS scores in the sitting and supine position at 1, 4, 8, 12, 16, and $20 \mathrm{~h}$ were significantly lower in the gabapentin group when compared with the placebo group upto $20 \mathrm{~h}$ after surgery. Fassoulaki et al. 28 , in contrast, were unable to demonstrate a decrease in analgesic consumption and VAS scores at rest and after movement during the first $24 \mathrm{~h}$ postoperatively in mastectomy surgery. They used gabapentin $400 \mathrm{mg}$ t.i.d.or mexiletine $200 \mathrm{mg}$ t.i.d.or placebo, for 10 days postoperatively. 1st dose was given on evening before surgery. Differences between results from our study can be attributed to difference in types of surgery and in use of different types of analgesics.

Gabapentin has been reported to be more effective when given preoperatively however, Pandey et al. 29 in their study reported that gabapentin $(600 \mathrm{mg})$, given preemptively or post incision did not have significant difference in fentanyl consumption between pre- and post-incision groups. However, 
our study has shown that gabapentin when given preoperatively has resulted in significant less morphine consumption. The findings are consistent with the studies ${ }^{4,25,30}$ in which gabapentin was used in the dose of $1200 \mathrm{mg}$, the same dose as used in our study. Pandey et al. ${ }^{29}$ and Giron et al. ${ }^{31}$ in their study reported a higher incidence of sedation in patients who received gabapentin. In the study by Gilron et al. ${ }^{31} 17.4 \%$ of patients in gabapentin group developed heavy sedation compared to placebo group $(\mathrm{P}<0.05)$. They had used gabapentin in the dose of $1800 \mathrm{mg}$ per day for three days, starting preoperatively on the day of surgery and continuing through the postoperative days one and two. Although more patients in gabapentin group developed intermittent sedation in our study compared to placebo group, it was statistically not significant $(p=0.4)$. The smaller dose of gabapentin in our study may have caused the difference. Although the elimination half-life of gabapentin is between 4.8 and $8.7 \mathrm{~h}$, persistence of sedation even during the latter period of the follow-up indicates that the sedative activity may have been due to epidural morphine instead. Additionally, $63.3 \%$ of patients in the placebo group who did not receive gabapentin also developed intermittent sedation. Therefore the sedative effect cannot be attributed to the use of gabapentin alone. A limitation of our study is that we did not have a dose-response data before choosing the dose of gabapentin in our study. Different studies have used gabapentin in different doses ranging from $300 \mathrm{mg}$ to $3000 \mathrm{mg}$. Some of the studies have used multiple dosing instead of a single preoperative dose like ours. So the conclusion about the optimal dose and duration of gabapentin cannot be made.

\section{CONCLUSION}

From this randomized, double blind, prospective study, we conclude that oral gabapentin, $1200 \mathrm{mg}$ as a premedication prolongs the analgesic effect of epidural morphine and decreases the postoperative epidural morphine consumption with significant reduction in pain scores at rest and during movement. As a part of multimodal analgesia, gabapentin is a useful adjuvant to epidural analgesia after total abdominal hysterectomy. Gabapentin can be an effective drug in the armamentarium of anesthesiologists in the treatment of postoperative pain.

\section{REFERENCES}

1. Merskey H. Pain terms: A supplementary note. Pain 1982; 14:205-206.

2. Sinatra RS, de Leon-Casasola OA, Ginsberg B, Viscusi ER, editors. Acute Pain Management. New York: Cambridge University Press; 2009.

3. Dahl JB, Mathiesen O, Moiniche S. Protective premedication: an option with gabapentin and related drugs? A review of gabapentin and pregabalin in the treatment of post-operative pain. Acta Anaesthesiol Scand 2004; 48: 1130-6.

4. Turan A, Kaya G, Karamanlioglu B, Pamukcu Z, Apfel CC. Effect of oral gabapentin on postoperative epidural analgesia. British Journal of Anaesthesia 2006; 96:242-24.

5. Mellob RD, Dickenson AH. Spinal cord mechanisms of pain. British Journal of Anaesthesia 2008; 101(1): 8-16.

6. Abram SE, editor. Pain medicine: the requisites in anesthesiology. Philadelphia (PA): Mosby; 2006.

7. Shorten G, Carr DB, Harmon D, Puig MM, Browne J, editors. Postoperative pain management: an evidence-based guide to practice. Philadelphia (PA): Saunders; 2006.

8. Postoperative Pain Management-Good Clinical Practice General recommendations and principles for successful pain management, European Society of Regional Anaesthesia and Pain Therapy.

9. Block BM, Liu SS, Rowlingson AJ, Cowan AR, Cowan JA, Wu CL. Efficacy of Postoperative Epidural Analgesia: A Meta-analysis. JAMA.2003; 290:2455-2463.

10. Barash PG, Cullen BF, Stoelting RK, editors. Clinical Anesthesia, 5th ed. Philadelphia (PA): Lippincott Williams \& Wilkins; 2001.

11. Dolin SJ, Cashman JN. Tolerability of acute postoperative pain management: nausea, vomiting, sedation, pruritis, and urinary retention. Evidence from published data. British Journal of Anaesthesia 2005; 95:584-91.

12. Macintyre PE, Schug SA, Scot DA, Visser EJ, Walker SM. Acute Pain Management: Scientific Evidence. 3rd edition. Melbourne: Australian and New Zealand College of Anaesthetists and Faculty of Pain Medicine; 2010.

13. Kissin I. Preemptive analgesia. Anesthesiology 2000; 93:1138-43.

14. Wilder-Smith $\mathrm{OH}$. Pre-emptive analgesia and surgical pain. Prog Brain Res 2000; 129:505-24.

15. Rosner H, Rubin L, Kestenbaum A. Gabapentin adjunctive therapy in neuropathic pain states. Clin J Pain 1996; 12:568.

16. Backonja M, Beydoun A, Edwards KR. Gabapentin for the symptomatic treatment of painful neuropathy in patients with diabetes mellitus: a randomized controlled trial. JAMA 1998; 280:1831-6.

17. Rowbotham M, Harden N, Stacey B, Bernstein P, Miller ML. Gabapentin for the treatment of postherpetic neuralgia: a randomized controlled trial. JAMA 1998; 280:1837-42.

18. Mellick GA, Mellick LB. Reflex sympathetic dystrophy treated with gabapentin. Arch Phys Med Rehabil 1997; 78:98-105.

19. Werner MU, Perkins FM, Holte K. Effects of gabapentin in acute inflammatory pain in humans. Reg Anesth Pain Med $2001 ; 26: 322-8$.

20. Gilron I. Is gabapentin a broad-spectrum analgesic? Anesthesiology 2002; 97:537-9.

21. Mao J, Chen LL. Gabapentin in pain management. Anesth Analg 2000; 91:680-7.

22. Eckhardt K, Ammon S, Hofmann U, Riebe A, Nadja G, Mikus G. Gabapentin enhances the analgesic effect of morphine. Anesth Analg 2000; 91: 185-191.

23. Tiippana EM, Hamunen K, Kontinen VK, Kalso E. Do surgical patients benefit from perioperative gabapentin/ pregabalin? A systematic review of efficacy and safety. Anesth Analg 2007; 104:1545-1556

24. Dierking G, Duedahl TH, Rasmussen ML, Fomsgaard JS, Moiniche S, Romsing $\mathrm{J}$, et al. Effects of gabapentin on 
postoperative morphine consumption and pain after abdominal hysterectomy: a randomized, double-blind trial. Acta Anaesthesiol Scand 2004; 48:322-7.

25. Turan A, Karamanlioglu B, Memis D, Usar P, Pamukcu Z, Ture M. The Analgesic Effects of Gabapentin after Total Abdominal Hysterectomy. Anesth Analg 2004; 98:1370-3.

26. Verma A, Arya S, Sahu S, Lata I, Pandey HD , Singh H. To Evaluate the Role of Gabapentin as Preemptive Analgesic in Patients Undergoing Total Abdominal Hysterectomy in Epidural Anaesthesia. Indian Journal of Anaesthesia 2008; 52 (4):428-431.

27. Dirks J, Fredensborg BB, Christensen D, Fomsgaard JS, Flyger H, Dahl JB. A randomized study of the effects of single-dose gabapentin versus placebo on postoperative pain and morphine consumption after mastectomy. Anesthesiology 2002; 97:560 - 4.

28. Fassoulaki A, Patris K, Sarantopoulos C, Hogan Q. The analgesic effect of gabapentin and mexiletine after breast surgery for cancer. Anesth Analg 2002; 95:985-91.

29. Pandey CK, Singhal V, Kumar M, Lakra A, Ranjan R, Pal $\mathrm{R}$, et al. Gabapentin provides effective postoperative analgesia whether administered preemptively or postincision. Can J Anesth 2005; 52:827-831.

30. Turan A, Memis D, Karamanlıglu B, Yagiz R, Pamukcu $Z$, Yavuz E. The Analgesic Effects of Gabapentin in Monitored Anesthesia Care for Ear-Nose-Throat Surgery. Anesth Analg 2004; 99:375 8

31. Gilron I, Orr E, Tu D, O’Neill JP, Zamora JE, Bell AC. A placebo controlled randomized clinical trial of perioperative administration of gabapentin, rofecoxib and their combination for spontaneous and movement-evoked pain after abdominal hysterectomy. Pain 2005; 113:191200. 